\section{PLAN CONTABLE GENERAL REVISADO}

CPC J. M. ENRIQUE ROJAS BORJAS

Al iniciar la exposición de este primer artículo, en el cual voy a exponer mi apreciación al Plan Contable General Revisado que se aplica en el Perú, es importante reconocer y agradecer la oportunidad que la doctora Beatriz Herrera García, directora del instituto de investigación de ciencias financieras y contables, nos está brindando para darnos a conocer a través de los artículos que se puedan publicar.

Mi experiencia profesional en el mundo de los negocios data desde el año 1960, fecha en la cual la actividad del contador no se sujetaba a una normatividad contable nacional; es decir, cada contador desarrollaba su conocimiento contable basado en las teorías más avanzadas de los países como Francia, Inglaterra, EE.UU. de Norteamérica, etc. Por ello, uno de los textos de mi consulta fue "El Manual del Contador" de W. A. Paton, en el cual se expone una carta de cuentas, la cual me servía de base para elaborar los planes de cuentas en las empresas donde trabajé inicialmente, las cuales estaban desarrollando actividades textiles, agrícolas, ganaderas, inmobiliarias, comerciales, servicios hospitalarios, financieras.

En el año 1994, se inicia la normalización contable en nuestro país. con la dación del D.L. N²0172, que obligó a las empresas a registrar sus operaciones bajo un sistema uniforme de contabilidad. Este primer plan contable general fue modificado por la CONASEV (Comisión Supervisora de Empresas y Valores) creando para este efecto un nuevo plan contable con el nombre de Plan Contable General Revisado, el cual no ha sido modificado hasta la fecha. Las instrucciones de esta normatividad establecen que todas las empresas deben elaborar sus propios planes de cuentas adecuados al Plan Contable General Revisado.

Es indudable reconocer que el marco jurídico que norman muchas actividades han variado sustancialmente; así como también. el uso de documentación mercantil que sustenten las operaciones mercantiles que registran las empresas, razones por las cuales se han creado nuevos planes contables para los sectores financieros mineros y en cuya creación no ha intervenido la CONASEV, situación por la cual resulta imperioso que los centros de investigación de las universidades se avoquen al estudio y formulación de nuevos planes contables, tomando en cuenta las actividades sectoriales y el marco jurídico que ha creado nuevas disposiciones legales que instituyen documentación mercantil, que no esté contemplada en el Plan Contable General Revisado.

Debo enfatizar especialmente la ley de comprobantes de pago, que dictamina una serie de documentos; que tienen particularidades especiales, tal como es el uso de la factura, boleta de venta, recibo de honorarios y otros, que deben ser citados en el plan contable en forma independiente.

Al desarrollar el plan contable de las empresas y al adecuarlas al Plan Contable General Revisado, nos encontramos que sólo se citan las facturas y las letras de cambio, tanto para la cuenta de clientes como las de proveedores, debiendo contemplarse que la ley de comprobantes de pago dictamine una dinámica para cada comprobante citado en esta ley.

El marco jurídico de los impuestos y 
las contribuciones, también ha variado con la creación de nuevos tributos que tampoco lo considera el Plan Contable General Revisado. Es necesario tomar en cuenta la situación de cambios que se están registrando en las actividades financieras y no financieras; motivo por el cual considero que es necesario crear planes contables para cada sector, que le permita al estado peruano medir el desarrollo de la actividad como sector a través de los estados financieros que se formulan, así podríamos tener los siguientes planes contables:

1) Para el sector comercio.

2) Para el sector industria textil.

3) Para el sector agropecuario.

4) Para el sector minero.

5) Para el sector educación.

6) Para el sector salud.

7) Para el sector servicios.

La metodología del uso de las clases $6,7,8,9$ y 0 debe ser definida con un criterio más técnico acorde con la realidad nacional.

Considero que este artículo debe ser analizado por todos los usuarios del Plan Contable General Revisado, para que éstos puedan sugerir sus opiniones. 